\title{
Design and Fabrication Testing of Combined Multipurpose Jig and Fixture
}

\author{
K. Nanthakumar ${ }^{1}$, V. Prabakaran ${ }^{2}$, \\ Department of Mechanical Engineering, Assistant Professor, Gnanamani College of Engineering ${ }^{1,2}$,
}

\begin{abstract}
This proposed method has to design and fabricate the Multipurpose Jig and Fixture, for that component which has been to reduce the manufacturing cycle time. When the component produced on a small size previously this is to produces the large quantities of requirements. The selective components requires for machining operations such as step milling, angle milling \& boring and reaming. The few operations where been done in CNC and rest operations are carried out in Conventional machine tool. The proposed method has to be design and fabricated the multi-operational Fixture for the complete machining operations in a single machining centre. The Fixture design has will serve for the economic production for the component.
\end{abstract}

\section{Introduction}

The successful running of all over mass production depends upon the interchange ability to facilitate easy to assembly and reduction of unit cost. There is a necessary of special purpose tools which are used to facilitate the production operation like as machining, assembling, intersecting, etc. to save the calculation time and efforts, four formulas and three analysis models were introduced for calculation of possible UMFs during the assembly process. For the shortest computation time design process [1]. A calibration method reduced from the cascading network relation has been presents to calibrate a symmetric device with an arbitrary test fixture by three measurements techniques. The result analysis indicates the obtained S-parameters of the test fixture have a large error. When the reflection coefficients of the DUT are low, but the calibrated S-parameters of the symmetric DUT is always accurate and even have lower errors than the results obtained by the TRL method [2].

A set of inequalities, which characterizes the relations between the different quality measures are established. The inequalities method shows that the encoded information of both location and accuracy, the capability in resting external loads. For that the fixture design on general 3-D objects, and all appropriate quality measures [3]. The analysis and design can proceeds step by step process the designed grasp configuration $G$ should be strongly accessible; The parameter combinations of (G,d) should be selected that locator configuration of $\mathrm{G}_{\mathrm{L}}$ is L-approachable the parameter combination $(\mathrm{G}, \mathrm{w}, \mathrm{d})$ must satisfies the stability and W-approachability conditions [4].

An analytical linear model is developed to describe the propagation of work piece and geometric deviation among them multiple machining stages. This linear model has a State- space form and the states are the work piece geometric deviations. With this model which integrates process and product information, modelbased fault diagnosis can be developed to quickly identify the faults [5]. The deflection quality measure is a frame invariant. Second, the quality measures apply to 2-D and 3-D compliant fixtures modelled by any quasigrid compliance model and employing any number of contacts. In order to reduce object deflection, the fixels should be placed on evenly oriented edges, Should spread apart with respect to the fixture's centre of compliance, and should minimize the distance from the object's centroid to the fixture's centre of compliance [6].

The method is applicable for all microwave fixtures, except for those characteristics are influenced by the relative positions of the adapters comprising the fixtures. In contrast to the self-calibration techniques, the method does not have any frequency limitations and does not need require any calibration standards for performing the experiments [7]. Furthermore, the results have given novel information about the effects of slots and ground-bar extensions on the ground-shielded test fixture parasitic component. To further optimize the layout of the ground shielded test fixture, it can be totally upgraded to fully shielded structure. This reduces the test fixture dangling leg impedance as validated by the experimental data [8].

In all cases, the careful definition of members based on manufacturing constraints and careful definition of KCs based on customers' needs should proceed, in order to avoid a large number of unpractical solutions. as the enumerative search presented does not only require a significant amount of computation, but conflicts with many practical constraints, it is not desirable to entrust the whole product geometry to the assembly synthesis method, especially when the product geometry is fairly complex [9].

Due to the singularity of the design matrix of a multi station fixture system, the widely used D-optimal criterion is not an appropriate design measure. The fixture system used in a four-station SUV side frame assembly process, the revised exchange algorithm yields the optimal fixture design the maximal sensitivity level 
is only $72.3 \%$ of the currently used fixture layout design. The reduction of $27.7 \%$ in sensitivity implies the same amount of reduction in product variation level under the same variation inputs, according to the definition of sensitivity.

\title{
II. Overview of Jig and Fixture JIG
}

A Jig is a one type of custom-made tool. It used to location and motion of another tool. A Jig is a primary purpose is to provide repeatability, accuracy, and interchange ability in the manufacturing products. The Jig's may be divided into two types of classes, Boring Jig and Drill Jig. Boring Jigs are used to bore the holes. Drilling may be divided into two general types, open and closed types. Open Jigs are simple operations and it is done on side of the part. Closed or fix jigs are used for parts.

\section{Fixture}

A Fixture is a work holding device used in the manufacturing industries. Fixtures are used to securely locate the position or location and to support the work, ensured that all parts produced using the fixture will maintain conformity and interchange ability. Using this fixture improves the economy of production by allowing smooth operation and quick transition from part to part production.

The Jig and Fixtures having some essential features,

They are;
a. Reduction of Idle time.
b. Cleanliness.
c. Standardization.
d. Hardened surfaces.
e. Position of clamps.

\section{A. Fundamental principles of Jig and fixture:}

\author{
i. Locating Points. \\ ii. Fool Proof. \\ iii. Clamping Device. \\ iv. Reduction of idle time. \\ v. Weight of Jigs and Fixture.
}

\section{B. Materials used in Jig and Fixture:}

The Jig and Fixture are made from variety of materials, some of which can be hardened or resist. It sometimes use non ferrous like as phosphor bronze to reduce the wear of mating parts or nylons or fibers to prevent damage. Most of us the high speed material has been used for this production.

\section{Design Procedure:}

The creative tool design method has design a jig or fixture through functional requirements. The goal is to find the balance combination at reasonable cost. Tool design is essentially an exercise in the problem solving.

\section{Design of Milling Fixture:}

The fixture is designed for vertical milling operations. According to this process plan there are three surface machined. The fixture is using for finishing operation. The rough milling will be performed with the magnetic bed by keeping $2 \mathrm{~mm}$ stock condition. After that drilling and reaming of $25 \mathrm{~mm}$ whole will be performed. The locating principles have helps to locate the point and to drill to a correct angle condition. The locating refers to the dimensional and position relationship between the work piece and the cutting tool. The locator establishes and maintains the position of part in a jig or fixture to ensure the repeatability of the work holder.

The mechanism of locating principle helps to find the degree of freedom and the six point location has to locates to 3 pins are fixed at the base, 2 in vertical plane and 1 in another vertical plane. The 3 planes are perpendicular to each other. The position and locator has helps to finding the position and then redundant location. The redundant location has to avoid the dust and duplicate particles. The fig 2 represents the locator size and tolerances. The work piece determines the overall size of the locating element. The MMC of feature is the size of the feature where it has the maximum amount of material. 


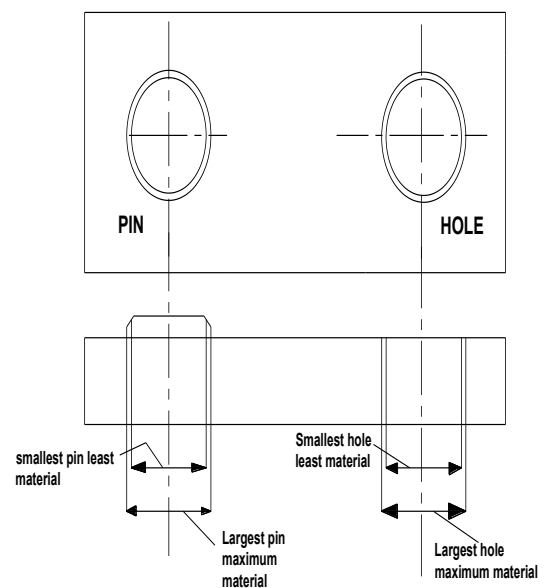

Fig 2. Locator size and Tolerance

A tolerance twice as tight might actually cost five times as much procedure. When a straight percentage value of $25 \%$ is applied to $0.50 \%$ work piece tolerance the work holder tolerance is $0.125 \%$. The table 1 contains for the material list.

\begin{tabular}{|l|l|l|l|}
\hline Name & Material & No & Process \\
\hline Base plate & Mild steel & 1 & Milling, Drilling Grinding \\
\hline Pillar & En8 & 4 & Hardening, turning, Grinding \\
\hline M12 & Mild steel & 6 & Standard \\
\hline Drill brush & OHNS & 3 & Standard \\
\hline Strap Clamp & C45 & 2 & Standard \\
\hline Locating Pin & En24 Mild Steel & 6 & Mill, grind, jig boring \\
\hline Jig Plate & En24 mild steel & 1 & Mill, Grind, Jig boring \\
\hline
\end{tabular}

Table 1. Material List

Selection of Bush

\section{Calculation}

Generally the outside diameter of the bush will be either push fit or press fit transition fit and inner hole of bush will be running fit.

(i) The diameter to be drill the work pieces $8 \mathrm{~mm}$

\{For $8 \mathrm{~mm}$, select bush of fixed type [DDB 5.100]\}

Inner diameter of bush $=\mathrm{d}_{1} \mathrm{~F}_{7 \varnothing}=8 \mathrm{~F}_{7 \varnothing}$

Outer diameter of bush $=\mathrm{d}_{2} \mathrm{~h}_{6 \emptyset}=12 \mathrm{~h}_{6 \varnothing}$

Other dimensions of bush,

$\mathrm{L}_{1}=20 \mathrm{~mm}, \quad \mathrm{~L}_{2}=18 \mathrm{~mm}, \quad \mathrm{~d}_{3}=18 \mathrm{~mm}$

Design of Jig Plate

Width of the jig plate $=\mathrm{W}_{\mathrm{w}}+\mathrm{L}_{\mathrm{p}}+$ clearance on both sides.

Where,

$\mathrm{W}_{\mathrm{w}}$ - work piece width $=100 \mathrm{~mm}$.

$\mathrm{L}_{\mathrm{p}}$ - Length of the pillar $=16 \mathrm{~mm}$

Clearance on both sides $=(15+4) \mathrm{mm}$.

Width of jig plate $=$

$100+16+[15+4]=135 \mathrm{~mm}$.

Length of the jig plate $=L_{w}+$ clearance on both sides.

Where,

$\mathrm{L}_{\mathrm{w}}$ - Length of work piece $\quad-70 \mathrm{~mm}$ Clearance on both sides

Length of jig plate- $70+[15+15]=100 \mathrm{~mm}$.

$-15 \mathrm{~mm}$.

Thickness of jig plat - distance $L_{1}$ of the bush.

Thickness of jig plate $\quad-20 \mathrm{~mm}$.

Design of Fixture Plate

Selection of Fixture

Number of jobs

-1 no 
Material - mild steel

Brindle hardness $\quad-229 \mathrm{BHN}$

Surface finish $-0.025 \mathrm{~mm}$ to $0.05 \mathrm{~mm}$.

Selection Locating Method

From the part drawing

$$
\begin{aligned}
\mathrm{a} & =68 \mathrm{~mm} \\
\mathrm{~b} & =245 \mathrm{~mm} \\
\mathrm{~d}_{\max } & =24 \mathrm{~mm}
\end{aligned}
$$

Select diameter $=8 \mathrm{~mm}$ cylindrical pin 5 number (DDB 5.92)

Selection of Clamping Method: is required.

To select required clamping device the clamping force should be calculated for which the cutting force

Cutting force $\mathrm{F}_{\mathrm{c}}=(405 \times \mathrm{kx} \mathrm{x} \mathrm{b \times d}) / \mathrm{C}_{\mathrm{g}}$

Material constant for

High carbon steel, $\quad \mathrm{k}=8.5$

Feed $\quad \mathrm{f}=75 \mathrm{~mm} / \mathrm{min}$.

Cutting speed $\quad \mathrm{C}_{\mathrm{g}}=15 \mathrm{~m} / \mathrm{min}$.

Cutting force $\quad \mathrm{F}_{\mathrm{c}}=(4.5 \times 8.5 \times 75 \times 3 \times 3) / 15=1721.25 \mathrm{~N}$.

Design of Fixture Body:

Width of the fixture plate $=\mathrm{W}_{\mathrm{w}}+$ clearance on both sides.

Where,

$\mathrm{W}_{\mathrm{w}}$ - work piece width $=100 \mathrm{~mm}$.

Clearance on both sides $=(31+4) \mathrm{mm}$.

Width of fixture plate $=100+(31+4)=135 \mathrm{~mm}$.

Length of the fixture plate $=\mathrm{L}_{\mathrm{w}}+$ clearance on both sides.

Where,

$\mathrm{L}_{\mathrm{W}}$ - Length of work piece $-70 \mathrm{~mm}$.

Clearance on both sides $\quad-(15+15) \mathrm{mm}$.

Length of fixture plate $-70+30=100 \mathrm{~mm}$

Force Calculation:

Drilling Force:

Drilling force $=1.16 \mathrm{x} \mathrm{k} \mathrm{d}(100 \mathrm{~s})^{0.85}$

Where,

$$
\begin{gathered}
\mathrm{k}=\text { material factor }-1.5 \text { for mild steel } \\
\mathrm{S}=\text { feed }=0.19 \mathrm{~mm} / \mathrm{rev} \\
\mathrm{D}=\text { diameter of drill }=12 \mathrm{~mm}
\end{gathered}
$$

Thrust force:

$$
\begin{aligned}
& \text { Thrust force }=1.16 \times 1.5 \times 25(100 \times 0.19) \\
& \text { Thrust force }=5313.9 \mathrm{~N} \\
& =531.39 \mathrm{Kgf} \\
& \left(\mathrm{P}_{\mathrm{z}}\right)=\left(\mathrm{K}_{\mathrm{s}} \times \mathrm{d} \times \mathrm{s}\right) / 4 \mathrm{M} \mathrm{Kgf} \\
& =\mathrm{d} \times \mathrm{s} / 4 \mathrm{~mm}^{2} \\
& =25 \times 0.19 / 4=1.188 \mathrm{~mm}^{2} \\
& 297 \mathrm{kgf}=2970 \mathrm{~N}
\end{aligned}
$$

Torque, $\mathrm{M}=\left(\mathrm{P}_{\mathrm{z}} \mathrm{x} \mathrm{d}\right) / 20$

$$
\begin{aligned}
& =(2970 \times 25) / 20 \\
M & =3712.5 \mathrm{~N}-\mathrm{mm}
\end{aligned}
$$

Clamping Force:

Clamping force $(\mathrm{Q})=$ drilling force $\mathrm{x}$ factor of safety

$$
=3712.5 \times 3=11137.5 \mathrm{~N}
$$


Clamping Force Analysis Of Strap Clamp:

Strap clamp calculation:

They are usually made to at least the same width as the washer under the head of the bolt used to tighten the clamp. The slots are made approximately $1.5748 \mathrm{~mm}$ wider than the diameter of the clamp,

$\mathrm{W}=2.8 \times \mathrm{x} \mathrm{d}+1.5748$

Where, $\mathrm{d}=10 \mathrm{~mm}$

$\mathrm{W}=29.5748 \sim 30 \mathrm{~mm}$

Thickness' $t$ ' of the clamp for a bolt diameter ' $d$ ' of is given by

$\mathrm{T}=[0.85 \times \mathrm{d} \times \mathrm{A}\{1-(\mathrm{A} / \mathrm{B})\}] \wedge 0.5$

$\mathrm{T}=[0.85 \times 10 \times 55 \times\{1-(55 / 75)\}] \wedge 0.5=14.88 \sim 15 \mathrm{~mm}$

The load $\mathrm{n}$ the bolt is a function of the torque on the bolt and the diameter of bolt.

Torque on the bolt, $\quad \mathrm{T}=(\mathrm{d} \times \mathrm{f}) / 5$

$\mathrm{F}=(\mathrm{Axf}) / \mathrm{B}$.

$\mathrm{F}=(5 \mathrm{xT}) / \mathrm{d}$

$=(5 \times 3510) / 10=1575 \mathrm{~N}$.

Thus,

$\mathrm{M}=\mathrm{f} \times \mathrm{Ax}(\mathrm{BxA}) / \mathrm{B}$

$=1575 \times 55 \times 20 / 75=22435.6 \mathrm{~N}-\mathrm{mm}$

The stress on the clamp is obtained as follows,

$\mathrm{S}=\mathrm{M} /$ (section modulus)

Section modulus $=\left[(\mathrm{w}-\mathrm{c}) \mathrm{xt}^{2}\right] / 6$

$\mathrm{S}=$ stress on the clamp, $\mathrm{N} / \mathrm{mm}^{2}$

Section modulus $=\left[(30-10) \times 15^{2}\right] / 6=750 \mathrm{~mm}^{3}$

Stress on clamp $=\mathrm{M} /$ (section modulus)

Stress,

$\mathrm{S} \quad=22435.6 / 750=29.78 \mathrm{~N} / \mathrm{mm}^{2}$

\section{A. Fabrication}

\section{Fabrication and Testing}

The process sheet consists of the material used, operation involved, for the each part of the fixture. The design and bill of material of the part is forwarded to the manufacturing division. The performed of the operation for each part is transferred to the concern without assembly.

\section{A. Testing}

After fabrication, the fixture is tested to check whether it satisfy the requirements. Then the fixture satisfied the requirements. Then it is tested with ten regular work pieces.

The design cost method has to contains for separately for as cost estimation and component existing method the cost of design in existing method is $\mathrm{Rs}=700$. cost estimation for the designed method $\mathrm{Rs}=625$. The total reduction cost is $\mathrm{Rs}=75$.

\section{B. Design Diagram}

The above diagram has represents for a overall design structure and it's implemented to the design diagram. The jig and fixture has used to reduce the design time and cost of the material.

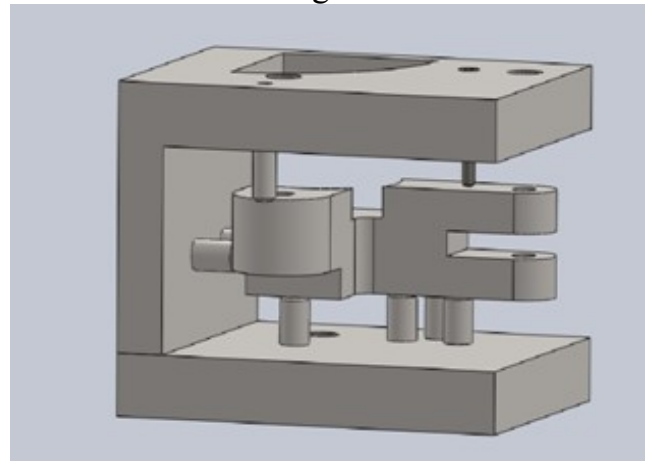

Fig 3. Design Diagram 
This diagram has to contain that design method of top plate section. This top plate section shows that over all view diagram of design.

\section{Conclusion}

Thus the multi-operational jig and fixture has been successfully designed and developed as per the requirements of the company from the existing model. The overall design method has to been designed to an separate analysis function. The top plate and screws and Nuts also designed for an particular dimension. The Jig and Fixture has helps to an reduce the cost and also saves the design time. This design can be the perfect solution for the problem that was sought out. The usage of this jig and fixture will certainly help the industry in reducing the production time and also reducing the production cost apart from increasing the productivity. The cost incurred in the manufacturing of the jig and fixture can be obtained in the passage of time without affecting the profit of the company.

The cost estimation Table is shown in below:

\begin{tabular}{|l|l|l|}
\hline & Existing method & $\begin{array}{l}\text { Newly designed } \\
\text { method }\end{array}$ \\
\hline Cost & $700 \mathrm{Rs}$ & $700-75=625 \mathrm{Rs}$ \\
\hline Time & $8319 \mathrm{sec}$ & $6532 \mathrm{sec}$ \\
\hline
\end{tabular}

Table 2. Comparison of Cost Estimation

The table has to been represents for as the existing method has to contains for the total service cost will be a Rs=700. In order to that the proposed method the design cost is reduced on $R s=75$. And design time will be low on $30 \mathrm{mins}$.

\section{References}

[1]. Ji-Young Lee, Do-Kwan Hong, Byung-Chul Woo, Dae-Suk Joo, Yo-Han Chio, and Byoung-Uk Nam,” Unbalanced Magnetic Force Calculation for Assembly Jig Design”, IEEE Transactions On Magnetics, Vol. 48, No. 11, November 2012.

[2]. Runbo Ma, Guorui Han, Xinwei Chen, and Wenmei Zhang," Calibrating an Arbitrary Test Fixture for a Symmetric Device by Three Measurements", IEEE Transactions On Instrumentation And Measurement, Vol. 59, No. 1, January 2010.

[3]. Xiangyang Zhu and Han Ding, Optimality Criteria for Fixture Layout Design: A Comparative Study", IEEE Transactions On Automation Science And Engineering, Vol. 6, No. 4, October 2009.

[4]. Youlun Xiong and Xiaorong Xiong," Algebraic Structure and Geometric Interpretation of Rigid Complex Fixture Systems", IEEE Transactions On Automation Science And Engineering, Vol. 4, No. 2, April 2007.

[5]. Jean-Philippe Loose, Shiyu Zhou, and Dariusz Ceglarek," Kinematic Analysis of Dimensional Variation Propagation for Multistage Machining Processes With General Fixture Layouts", IEEE Transactions On Automation Science And Engineering, Vol. 4, No. 2, April 2007.

[6]. Qiao Lin, Joel W. Burdick, and Elon Rimon, Constructing Minimum Deflection Fixture Arrangements Using Frame Invariant Norms", IEEE Transactions On Automation Science And Engineering, Vol. 3, No. 3, July 2006.

[7]. Alexei S. Adalev, Nikolay V. Korovkin, Masashi Hayakawa, and Jürgen B. Nitsch," Deembedding and Unterminating Microwave Fixtures With the Genetic Algorithm”, IEEE Transactions On Microwave Theory And Techniques, Vol. 54, No. 7, July 2006.

[8]. Tero Kaija and Pekka Heino," The Optimization of On-Wafer Shield-Based Test Fixture Layout”, IEEE Transactions On Microwave Theory And Techniques, Vol. 54, No. 5, May 2006.

[9]. Byungwoo Lee and Kazuhiro Saitou," Integrated Synthesis of Assembly and Fixture Scheme for Properly Constrained Assembly", IEEE Transactions On Automation Science And Engineering, Vol. 2, No. 3, July 2005.

[10]. Pansoo Kim and Yu Ding," Optimal Design of Fixture Layout in Multistation Assembly Processes", IEEE Transactions On Automation Science And Engineering, Vol. 1, No. 2, October 2004.

[11]. Kota Ohashi, Nobuhiko Hata, Tomoko Matsumura, Toru Ogata, Naoki Yahagi, Ichiro Sakuma, and Takeyoshi Dohi," Stem Cell Harvesting Device With Passive Flexible Drilling Unit for Bone Marrow Transplantation”, IEEE Transactions On Robotics And Automation, Vol. 19, No. 5, October 2003.

[12]. Allen G. Morinec, "Power Quality Considerations for CNC Machines: Grounding", IEEE Transactions On Industry Applications, Vol. 38, No. 1, January/February 2002. 